ISSN 1112-9867

Available online at

http://www.jfas.info

\title{
EVALUATION OF THE ANTIOXIDANT ACTIVITY OF POTATOES BY RADICAL SCAVENGING ACTIVITY USING $\mathrm{O}_{2}^{-}$AND DPPH
}

\author{
K. Ben Haoua ${ }^{* 1,2}$, T. Lanez ${ }^{1}$ \\ ${ }^{1}$ El Oued University, VTRS laboratory, PO Box 789, 39000, El Oued, Algeria \\ ${ }^{2}$ Biskra University, Chemistry Department, PO Box 145, Biskra 07000, Biskra, Algeria
}

Received: 23 June 2017/ Accepted: 13 December 2017 / Published online: 01 January 2018

\begin{abstract}
This work aimed to evaluate the antioxidant capacity (AC), total phenolic (TPC) and flavonoids content (TFC) of the ethanolic extracts four vraities of Solanum tuberosum $L$ (potato), TPC of whole roots shows values ranged from 19.21 to $08.88 \mathrm{mg} \mathrm{AG} / \mathrm{g}$ of extract and $\mathrm{TFC}$ varied from 25.03 to $10.91 \mathrm{mg}$ rutin/g of extract. However, this phytochemical content of sample extracts had an effect on the AC, measured with scavenging radical activity using 2,2-diphenyl-1-picrylhydrazyl (DPPH) and superoxide anion radicals $\left(\mathrm{O}_{2}{ }^{-}\right)$. The $\mathrm{IC}_{50}$ values measured using superoxide anion radical $\left(\mathrm{O}_{2}{ }_{2}^{-}\right)$and $\mathrm{DPPH}$ ranged from 1.03 to $1.81 \mathrm{mg} / \mathrm{ml}$ and from 1.21 to $3.86 \mathrm{mg} / \mathrm{ml}$ respectively. Free binding energies and binding constants of ethanolic extracts contents and $\mathrm{O}_{2}^{-}$were also determinated.
\end{abstract}

Keywords: antioxidant; flavonoids; phenolic; potatoes; DPPH; Cyclic voltametry; superoxide anion radical.

Author Correspondence, e-mail: mohamesnoua@gmail.com

doi: http://dx.doi.org/10.4314/jfas.v10i1.12

\section{INTRODUCTION}

A free radical is defined as an atom or molecule containing one or more unpaired electrons that are capable of free existence [1]. Free radicals are generated during normal respiration and cellular functions. Under normal physiological conditions, approximately $2 \%$ of oxygen consumed by the human body during respiration is converted into superoxide anion free radical, which is negatively charged $\left(\mathrm{O}_{2}^{-}{ }^{-}\right)$[2]. To survive in an unfriendly oxygen 
environment, living organisms generate water- and lipid-soluble antioxidants that can neutralize these highly reactive free radicals [3]. If the body's antioxidant mechanism does not operate optimally, excess free radicals can damage various bimolecular, including lipids, proteins, carbohydrates, and nucleic acids. A variety of free radical scavenging antioxidants is found in dietary sources like fruits and vegetables which were known as a phytochemicals compounds. These chemicals are classified as primary or secondary constituents, depending on their role in plant metabolism. Primary constituents include the common sugars, amino acids, proteins, purines and pyrimidines of nucleic acids, chlorophylls etc. Secondary constituents are the remaining plant chemicals such as alkaloids (derived from amino acids), terpenes (a group of lipids) and phenolics (derived from carbohydrates) [4]. Consequently, characterization of polyphenols as antioxidants is essential for both plant biology and human nutrition. Flavonoids, as well as many other plant polyphenols, possess a chemical structure ideal for free radical scavenging [5]. Their antioxidant properties include reactivity to a variety of reactive oxygen species [6-7]. There are two mechanisms for the radical scavenging reactions of phenolic antioxidants: a hydrogen atom transfer from the phenolic $\mathrm{OH}$ group; and an electron transfer followed by a proton transfer. The most frequently used free radicals are 2,2-diphenyl-1-picrylhydrazyl (DPPH [8]) and the cation radical of 2,21azinobis(3-ethylbenzothiazoline)-6-sulfonate (ABTS) of the Trolox Equivalent Antioxidant Capacity (TEAC) assay [9].

The objective of the current study was to evaluate the antioxidant property of phenolics extracted from the vegetable tissues of varieties of potatoes by scavenging activity of DPPH (diphenyl-picryl-hydrazyl) and the inhibitory effect of superoxide anion radicals.

\section{MATERIALS AND METHODS}

\subsection{Chemical and reagents}

Folin-Coiocaltau's reagent (solution 2M) was purchased from Sigma-Aldrich (Finland), gallic acid (99\%), rutin (97\%), Hydrochloric acid was provided by Rathburn Chemical (Walkerburn, Peebleshire, UK). Ethanol and di-sodium hydrogen phosphate were purchased from Fisher Scientific (Loughborough, UK), N, N-dimethylformamide (DMF) (analytical grade from PROLABO) was used as solvent without any purification, tetrabutylammonium tetrafluoroborate $\left(\mathrm{Bu}_{4} \mathrm{NBF}_{4}\right)$ (electrochemical grade (99\%) Sigma-Aldrich) was used as supporting electrolyte and its concentration was kept $0.1 \mathrm{M}$.

\subsection{Instrument}


UV-Vis experiments were performed using a UV-1800 UV-VIS spectrophotometer (Shimadzu Scientific Instruments, Kyoto, Japan).

Voltammetric measurements were carried out using voltalab40 (radiometer analytical SAS) in a double-walled electrochemical cell of $25 \mathrm{~mL}$, and a conventional three-electrode system was employed. A glassy carbon (GC) working electrode having area $0.013 \mathrm{~cm}^{2}$, a platinum wire counter electrode and an $\mathrm{Hg} / \mathrm{Hg} 2 \mathrm{Cl}$ reference electrode $(3.0 \mathrm{M} \mathrm{KCl})$ were used. The scan rate was kept at $100 \mathrm{mV} / \mathrm{s}$, and the potential window was from -1.4 to $0.0 \mathrm{~V}$. The studied extract samples were added to the in situ generated superoxide anion radical $\mathrm{O}_{2}^{-}$, and the cyclic voltammograms were recorded.

WUC-D06H, Daihan Scientific, Korea) was used for ultrasound-assisted extraction.

\subsection{Plant material}

Four potatoes cultivars 'Bartina, Kuroda, Kondor and Spunta' were collected in March 2015 from different areas located in the region of El-Oued south-east of Algeria, were grown for three months before being used.

\subsection{Preparation of extracts}

The ultrasound assisted extraction procedure was used for the extraction of potato. Thus 120 $\mathrm{ml}$ of solvent ethanol were added to $20 \mathrm{~g}$ of fresh potatoes cutting into $5 \mathrm{~mm}$ thick slices, the mixture was sonicated in an ultrasonic bath for $30 \mathrm{~min}$. then kept macerating for 2 hours. The extract was filtered through to remove all of the potato particles and the filtrate was concentrated under reduced pressure at $60{ }^{\circ} \mathrm{C}$ using rotary evaporator and stored in a refrigerator.

\section{PHYTOCHEMICAL INVESTIGATION}

\subsection{Total Polyphenol content}

TPC was determined with the Folin-Ciocalteu reagent following the method described by Singelton-Ross [10]. Briefly, $100 \mu \mathrm{L}$ of suitably diluted extract was added to $0.5 \mathrm{~mL}$ of newly diluted 10-fold Folin-Ciocalteu reagent. Then $2 \mathrm{~mL}$ of $20 \%$ aqueous $\mathrm{Na}_{2} \mathrm{CO}_{3}$ solution was added. The mixture was stand in the dark for half an hour, and then the absorbance was measured at $760 \mathrm{~nm}$ against a blank solution. Gallic acid was used as a reference and the results were presented as gallic acid equivalents/g of extract.

\subsection{Total flavonoids content}

TFC was determined as described by Zou [11]. A mixture of $1 \mathrm{ml}$ of extract, $2 \mathrm{ml}$ of distilled water and $0.15 \mathrm{ml}$ of $5 \% \mathrm{NaNO}_{2}$ was prepared and allowed to react for 6 min. then $0.15 \mathrm{ml}$ of 
$10 \% \mathrm{AlCl}_{3}$ solution was added and mixed stirred thoroughly. After $6 \mathrm{~min}, 2 \mathrm{ml}$ of $4 \% \mathrm{NaOH}$ solution was added and allowed to stand for another $15 \mathrm{~min}$. The absorbance of the mixture was measured at $510 \mathrm{~nm}$ versus prepared blank solution. Rutin was used as a standard for the quantification of TFC. Results were expressed in $\mathrm{mg}$ of rutin equivalents/g of extract.

\section{ANTIOXIDANT ACTIVITY}

\subsection{DPPH assay}

The scavenging activity by the DPPH (2,2-diphenyl-1-picrylhydrazyl) radical scavenging method according to Ohinishi and others [12]. with some modifications, a $1 \mathrm{ml}$ of diluted extract and $1 \mathrm{ml}$ of DPPH $(0.25 \mathrm{mM})$ were mixed, and after $30 \mathrm{~min}$ the absorbance was measured at $517 \mathrm{~nm}$. The scavenging activity was measured as the decrease in absorbance of the samples versus DPPH standard solution. Results were expressed as radical scavenging activity percentage (\%) of the DPPH according to the formula:

$$
I \%=\frac{\mathrm{A}_{0}-\mathrm{A}_{\mathrm{S}}}{\mathrm{A}_{0}} \times 100
$$

where: $A_{0}$ : absorbance of the control and $A_{S}$ : absorbance of the sample.

\subsection{Scavenging activity of superoxide anion $\mathrm{O}_{2}^{-}$radicals}

Superoxide anion radical was generated electrochemically by the reduction of commercial dioxygen in ACN containing $0.1 \mathrm{M} \mathrm{TBFB}$ at $28 \pm 1{ }^{\circ} \mathrm{C}$. The studied extract samples were added to this in situ generated $\mathrm{O}_{2}^{-}$, and the cyclic voltammograms were recorded following the method of Le Bourvellec [13].

The ability of the test sample to quench $\mathrm{O}_{2}^{-}\left(\%\right.$ inhibition of $\left.\mathrm{O}_{2}^{-}{ }^{-}\right)$was calculated using the following equation (2) [13,14],

$$
I \%=\frac{\mathrm{i}_{0}-\mathrm{i}_{\mathrm{S}}}{\mathrm{i}_{0}} \times 100
$$

where : $\mathrm{i}_{0}$ and $\mathrm{i}_{\mathrm{S}}$ are respectively the anodic peak current density of $\mathrm{O}_{2}^{-}$in the absence and in the presence of sample extract.

\subsection{Determination of $\mathrm{IC}_{50}$ values}

On the basis of screening results of triplicate measurement of the extract, the inhibition concentration values $\mathrm{IC}_{50}$ was determined from extrapolating the graph of scavenging activity versus the concentration of extract using linear regression analysis[15].

\subsection{Statistical analysis}


All the experiments were performed in triplicate, and the results were expressed as mean \pm

SD (standard deviation). Statistical analysis was performed using Minitab version 14 and Excel 2007 the results were significantly $(P \leq 0.005)$.

\section{RESULTS AND DISCUSSION}

\subsection{Phytochemical contents}

Table 1 shows TPC and TFC of potato samples. The amount of TPC from tuber ranged from 19.2144 to $08.8853 \mathrm{mg} \mathrm{GA} / \mathrm{g}$ of extract, the results of different extracts showed that the amount of TFC varied considerably from 10.9129 to $25.0350 \mathrm{mg}$ rutin/g of extract. Overall the results indicate that all of the ethanolic extract of four kinds has amount of phenolics and flavonoids compound but their content in ethanolic extract increasing in order was: Kondor > Bartina $>$ Spunta $>$ Kuroda.

Table 1. Determination of total Phenolics contents and total flavonoids of four kinds of potatoes

\begin{tabular}{ccc}
\hline Sample & TPC (mg GA*/g of extract) & TFC (mg rutin/g of extract) \\
\hline Kondor $^{*}$ & $19.2144 \pm 0.096$ & $25.0350 \pm 0.125$ \\
Bartina $^{*}$ & $18.9596 \pm 0.094$ & $23.5592 \pm 0.235$ \\
Spunta $^{* *}$ & $12.4628 \pm 0.124$ & $21.8057 \pm 0.218$ \\
kuroda $^{*}$ & $08.8853 \pm 0.088$ & $10.9129 \pm 0.076$ \\
$*=$ red tuber, $* *=$ yellow tuber
\end{tabular}

\subsection{Total antioxidant activity}
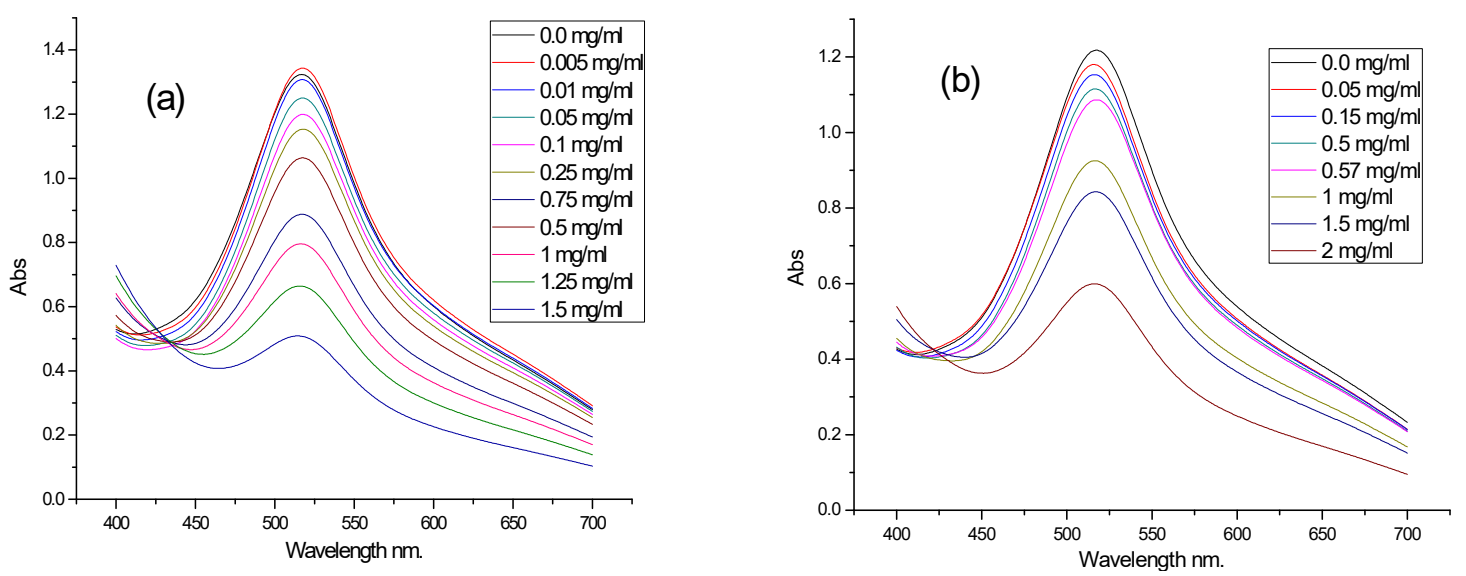

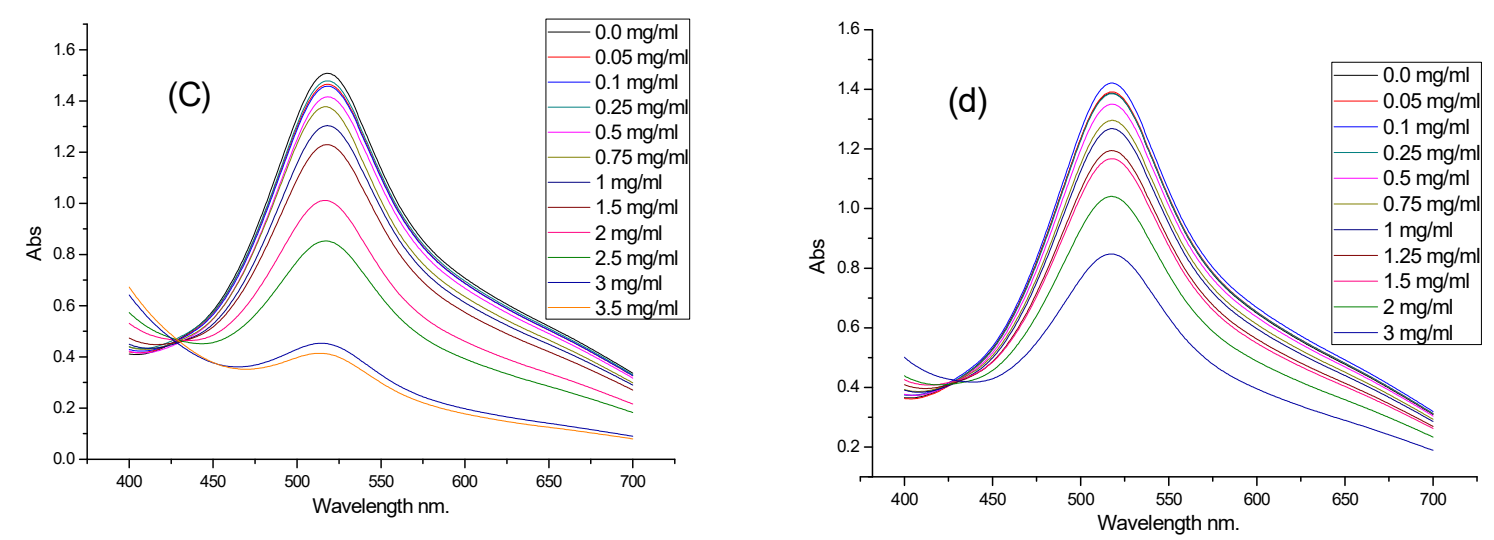

Fig.1. Electronic absorption spectra of $0.25 \mathrm{mM}$ of DPPH interaction with (a) Kondor, (b) Bartina, (c) Spunta, (d) Kuroda

The antioxidant capacities of potato extracts in term of $\mathrm{IC}_{50}$ were measured using DPPH and $\mathrm{O}_{2}^{-}$radical scavenging activity figure 1 and 3 . The equation obtained from the linear calibration graph in the studied concentration range of sample extract is presented in table 2 where y stand for the value of absorbance DPPH or the oxidation peak current density of $\mathrm{O}_{2}^{-}$ and $\mathrm{x}$ represents the value of the concentration of ethanolic extracts, expressed as $\mathrm{mg} / \mathrm{mL}$. Both methods show that the Kondor extracts have lower $\mathrm{IC}_{50}$ values of 1.21 and $1.03 \mathrm{mg} / \mathrm{mL}$ for DPPH and $\mathrm{O}_{2}^{-}$respectively, whereas Kuroda sample has $3.867 \mathrm{mg} / \mathrm{mL}(\mathrm{DPPH})$ and 1.819 $\mathrm{mg} / \mathrm{mL}$ for $\left(\mathrm{O}_{2}^{-}\right)$radical scavenging activity. All the $\mathrm{IC}_{50}$ values were considered as very statistically significant with $\mathrm{p}<0.005$. 
Table 2. $\mathrm{IC}_{50}$ values of sample extracts using DPPH and $\mathrm{O}_{2}^{-}$radical scavenging activity

\begin{tabular}{|c|c|c|c|c|}
\hline Sample & Equation & $\mathbf{R}^{2}$ value & IC $_{\mathbf{5 0}}{ }^{*}$ & P \\
\hline Kondor & $\mathrm{Y}=3.33+38.3 \mathrm{X}$ & 0.994 & 1.21 & 0.000 \\
\hline Bartina & $\mathrm{Y}=-0.44+23.7 \mathrm{X}$ & 0.968 & 2.12 & 0.000 \\
\hline Spunta & $\mathrm{Y}=-4.53+21.4 \mathrm{X}$ & 0.952 & 2.54 & 0.000 \\
\hline Kuroda & $\mathrm{Y}=-5.30+14.3 \mathrm{X}$ & 0.973 & 3.86 & 0.000 \\
\hline & Equation & $\mathbf{O}_{\mathbf{2}}^{-\mathbf{R}^{2}}$ value & $\mathbf{I C}_{\mathbf{5 0}}{ }^{*}$ & $\mathbf{P}$ \\
\hline Kondor & $\mathrm{Y}=1.56+46.8 \mathrm{X}$ & 0.989 & 1.0350 & 0.000 \\
\hline Bartina & $\mathrm{Y}=-7.52+50.6 \mathrm{X}$ & 0.923 & 1.1367 & 0.002 \\
\hline Spunta & $\mathrm{Y}=-0.134+27.6 \mathrm{X}$ & 0.988 & 1.8164 & 0.000 \\
\hline Kuroda & $\mathrm{Y}=-4.23+29.8 \mathrm{X}$ & 0.987 & 1.8197 & 0.000 \\
\hline
\end{tabular}

* Inhibition expressed as $\mathrm{mg} / \mathrm{ml}$

\subsection{Voltammetric Studies of $\mathrm{O}_{2}^{-}-$sample interaction}

Figure 2 shows the CV's behavior of oxygen-saturated DMF/0.1 TBFP in the potential window of -1.4 to $0.0 \mathrm{~V}$ at a glassy carbon electrode in the absence and presence of $0.4 \mathrm{~mL}$ sample extracts. The CV technique was also used for the determination of the binding constants and mode of interaction of the extract with $\mathrm{O}_{2}^{-}$in the same manner, used for study of binding of drug molecules to DNA[16-17]..

By adding $0.4 \mathrm{ml}$ of sample extracts in DMF solution, the anodic peak potential of $\mathrm{O}_{2}^{-}$was shifted by $\Delta \mathrm{E}$, to more negative values for $\mathrm{O}_{2}^{-}-$Kondor and to more positive values for the other samples, these shifts were associated with the decrease in oxidation peak current densities $\Delta \mathrm{ip}_{\mathrm{a}} \%$ which confirms the interaction of ethanolic extracts with $\mathrm{O}_{2}^{-}$(table3) The significant decrease in oxidation peak current densities can be attributed to the diminution in $\mathrm{O}_{2}^{-}$concentration due to the formation of sample extract complex.

Table 3. Shifts in peak potential and a decrease in anodic peak current of $\mathrm{O}_{2}^{-}$bound forms of extract samples.

\begin{tabular}{|c|c|c|c|c|c|c|c|}
\hline Sample & $I p_{a}(\mu A)$ & $E p_{a}(V)$ & $E p_{c}(V)$ & $E_{f}^{0}(V)$ & $\Delta E_{f}^{0}(m V)$ & $\Delta I p_{a} \%$ & $K_{o x} / K_{\text {red }}$ \\
\hline $\mathrm{O}_{2}^{-}$ & 134.2672 & -0.7068 & -0.7247 & -0.7157 & - & - & - \\
\hline $\mathrm{O}_{2}^{-}-$-Kondor & 104.2637 & -0.678 & -0.7566 & -0.7173 & -1.5574 & 22.3460 & 0.94 \\
\hline $\mathrm{O}_{2}^{-}$ & 137.3784 & -0.7251 & -0.7714 & -0.7482 & - & - & - \\
\hline $\mathrm{O}_{2}^{-}-$-Bartina & 118.844 & -0.7251 & -0.7624 & -0.7438 & 4.4776 & 13.4914 & 1.19 \\
\hline $\mathrm{O}_{2}^{-}$ & 137.5848 & -0.7149 & -0.7438 & -0.7294 & - & - & - \\
\hline $\mathrm{O}_{2}^{-}-$-Spunta & 114.627 & -0.7021 & -0.7477 & -0.7249 & 4.4776 & 16.6863 & 1.19 \\
\hline $\mathrm{O}_{2}^{-}$ & 142.4359 & -0.7613 & -0.7800 & -0.7706 & - & - & - \\
\hline $\mathrm{O}_{2}^{-}-$-Kuroda & 123.7957 & -0.7519 & -0.7617 & -0.7568 & 13.8221 & 13.0867 & 1.71 \\
\hline
\end{tabular}



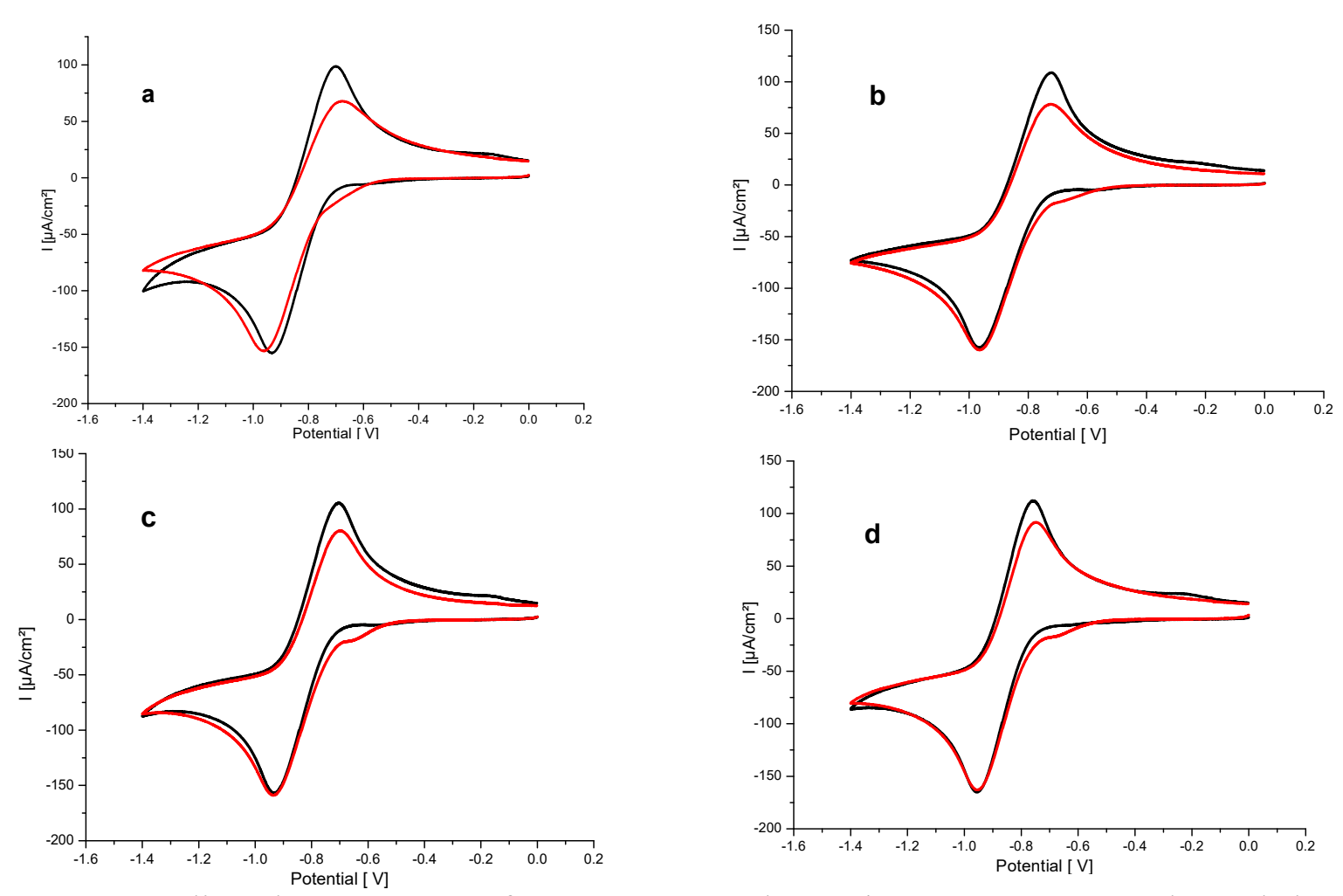

Fig.2. Cyclic voltammograms of oxygen-saturated DMF/0.1 TBFP on a GC electrode in the absence (black line) and in presence of $0.4 \mathrm{ml}$ sample extract (a) Kondor, (b) Bartina, (c) Spunta, (d) Kuroda at Scan rate $100 \mathrm{mV} \cdot \mathrm{s}^{-1}, \mathrm{~T}=28^{\circ}$

\subsection{Ratio of binding constants (Kox/Kred)}

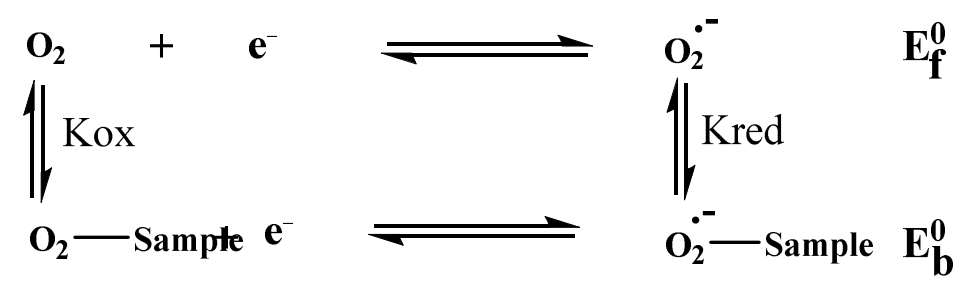

Scheme1: The redox behavior of the free radical and its bounded forms SE

The peak potential shift values additionally pointed out that $\mathrm{O}_{2}^{-}$is easier to oxidize in the presence of ethanolic extract because its reduced form $\mathrm{O}_{2}^{-}$is more strongly bound to extract than its oxidized form. For such a system, where both forms of the $\mathrm{O}_{2} / \mathrm{O}_{2}^{-}$redox couple interact with the potential antioxidant compound, scheme 2 can be applied [18]. Based on the process presented in scheme 2, the following equation is obtained [19],

$E_{b}^{0}-E_{f}^{0}=0.059 \log \frac{K_{r e d}}{K_{o x}}$ 
Where $E_{b}^{0}$ and $E_{f}^{0}$ are the formal potentials of the $\mathrm{O}_{2} / \mathrm{O}_{2}^{-}$redox couple in the free and bound forms, respectively. $E^{0}$ and $\Delta E^{0}$ are calculated using the following formulas (4) and (5)

$E^{0}=\left|\frac{E_{P c}+E_{P a}}{2}\right|$

$\Delta E^{0}=E^{0}\left(O_{2}^{\bullet-}-S E\right)-E^{0}\left(O_{2}^{\bullet-}\right)=E_{b}^{0}-E_{f}^{0}$
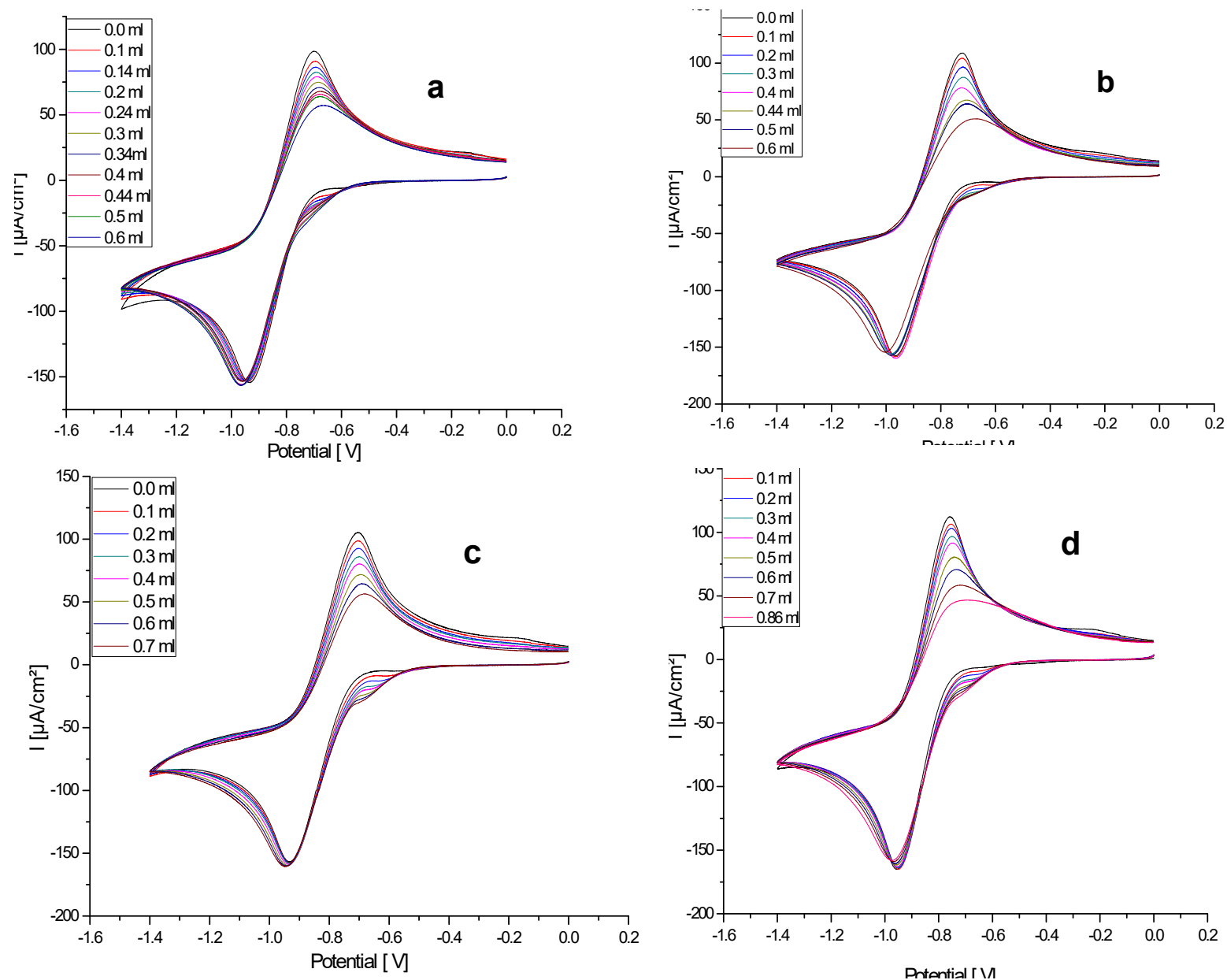

Fig.3. Cyclic voltammograms of oxygen-saturated DMF/0.1 TBFP on a GC electrode in the absence and presence of different concentration of sample extract (a) Kondor, (b) Bartina, (c) Spunta, (d) Kuroda at scan rate $100 \mathrm{mV} \cdot \mathrm{s}^{-1}, \mathrm{~T}=28^{\circ}$

\subsection{Thermodynamic properties}

To quantify the results, the strength of interaction, between superoxide anion radical and the probable antioxidant in the extract, was estimated in terms of binding constant $\mathrm{K}_{\mathrm{b}}$. Based on the decrease in peak current, the binding constant $\left(\mathrm{K}_{\mathrm{b}}\right)$ was calculated using following equation of Feng (6) [20]. 
$\log \left[\frac{1}{[A O]}\right]=\log K_{b}+\log \left[\frac{I_{p}}{I_{p o}-I_{p}}\right]$

Where, $\mathrm{Ip}_{\mathrm{o}}$ and Ip are the peak currents of superoxide anion radical in the absence and presence of additives, respectively, $[\mathrm{AO}]$ is the concentration of the antioxidant. As $[\mathrm{AO}]$ is not known, therefore, this term was replaced by the volume of the extracts ( $\Delta$ Vext). It is noticeable that the volume of the solution containing $\mathrm{O}_{2}^{-}$is fixed thus the addition of volume increments of the extract is proportional to the addition of more number of moles (i.e. concentration) of the compound(s) according to Safeer et al [21]. Another thermodynamic parameter, standard Gibbs free energy $\left(\Delta \mathrm{G}^{\circ}\right)$ was calculated using the measured $\mathrm{Kb}$.

The obtained values from CV's voltammograms showed in table 3 indicated that the binding constant is in the following ordre,

$$
K_{O_{2}^{\bullet-}-\text { Spunta }}<K_{O_{2}^{\bullet--K o n d o r ~}}<K_{O_{2}^{\bullet--K u r o d a}}<K_{O_{2}^{\bullet--B a r t i n a ~}}
$$

The values of free energy varied in the same order as of the binding constant. The negative values of $\Delta \mathrm{G}$ indicated the spontaneity of $\mathrm{O}_{2}^{--}-$sample interaction. The data obtained in table 3 were very statistically significant with $\mathrm{p}<0.005$

Table 3. Values of binding constants and binding free energies

\begin{tabular}{|c|c|c|c|c|c|}
\hline Compound & Equation & $\mathbf{R}^{2}$ & $\mathbf{K}$ & $\Delta \mathbf{G}$ & $\mathbf{P}$ \\
\hline $\mathrm{O}_{2}^{-}{ }^{-}$-Kondor & $\mathrm{y}=0.9086 \mathrm{x}+2.8778$ & 0.990 & $7.5474 \times 10^{2}$ & -16.42 & 0.000 \\
\hline $\mathrm{O}_{2}^{-}$-Bartina & $\mathrm{y}=0.4818 \mathrm{x}+3.1119$ & 0.956 & $13.1522 \times 10^{2}$ & -17.80 & 0.001 \\
\hline $\mathrm{O}_{2}^{\cdot}{ }^{-}$-Spunta & $\mathrm{y}=0.8952 \mathrm{x}+2.8012$ & 0.986 & $6.3270 \times 10^{2}$ & -15.99 & 0.000 \\
\hline $\mathrm{O}_{2}^{-}{ }^{-}$-Kuroda & $\mathrm{y}=0.576 \mathrm{x}+2.9473$ & 0.986 & $8.8572 \times 10^{2}$ & -16.82 & 0.000 \\
\hline
\end{tabular}

\subsection{Diffusion coefficients}

The redox process of the four sample extracts as a function to scan rates presented in Fig4. The voltammogram contained a couple of a clear stable oxidation and reduction peaks attributed to the electrochemical behaviour of the redox $\mathrm{O}_{2} / \mathrm{O}_{2}^{-}$couple. In addition, demonstrate clearly the reversibility of the oxidation reaction of the redox couple $\mathrm{O}_{2} / \mathrm{O}_{2}^{-}$as the oxidation peak potentials are not significantly affected by the variation in the scan rate.

The diffusion coefficients of the free radical $\mathrm{O}_{2}^{-}$and its $\mathrm{O}_{2}^{-}$bounded forms with ethanolic extract were calculated from the following Randles-Sevcik equation [22].

$i=2.69 \times 10^{5} n^{\frac{3}{2}} S C D^{\frac{1}{2}} v^{\frac{1}{2}}$

Where $i$ presents the oxidation peak current density, $S$ presents the surface of the working electrode $\left(\mathrm{cm}^{2}\right), C$ is the bulk concentration $\left(\mathrm{mol} . \mathrm{cm}^{-3}\right)$ of the electroactive species, $D$ present 
the diffusion coefficient $\left(\mathrm{cm}^{2} / \mathrm{s}\right)$ and $\mathrm{v}$ is the scan rate $(\mathrm{V} / \mathrm{s})$. The linearity of the plot $i p_{a}=f\left(v^{\frac{1}{2}}\right) \quad$ of the four adducts. Further demonstrates that the kinetic of the oxidation reaction is limited by the diffusion process. The diffusion coefficients were determined from the slopes of the plot $i p_{a}$ vs $v^{\frac{1}{2}}$. Values are given in Table 4 .

Table 4 shows that the diffusion coefficient of complexes $O_{2}^{--}-S E$ is lower than that of the free $\mathrm{O}_{2}^{-}$radical. The diffusion coefficients of four adducts are very close because sample complexes have the same contents the slight difference can only be attributed to the amount of the phytochemical compound.
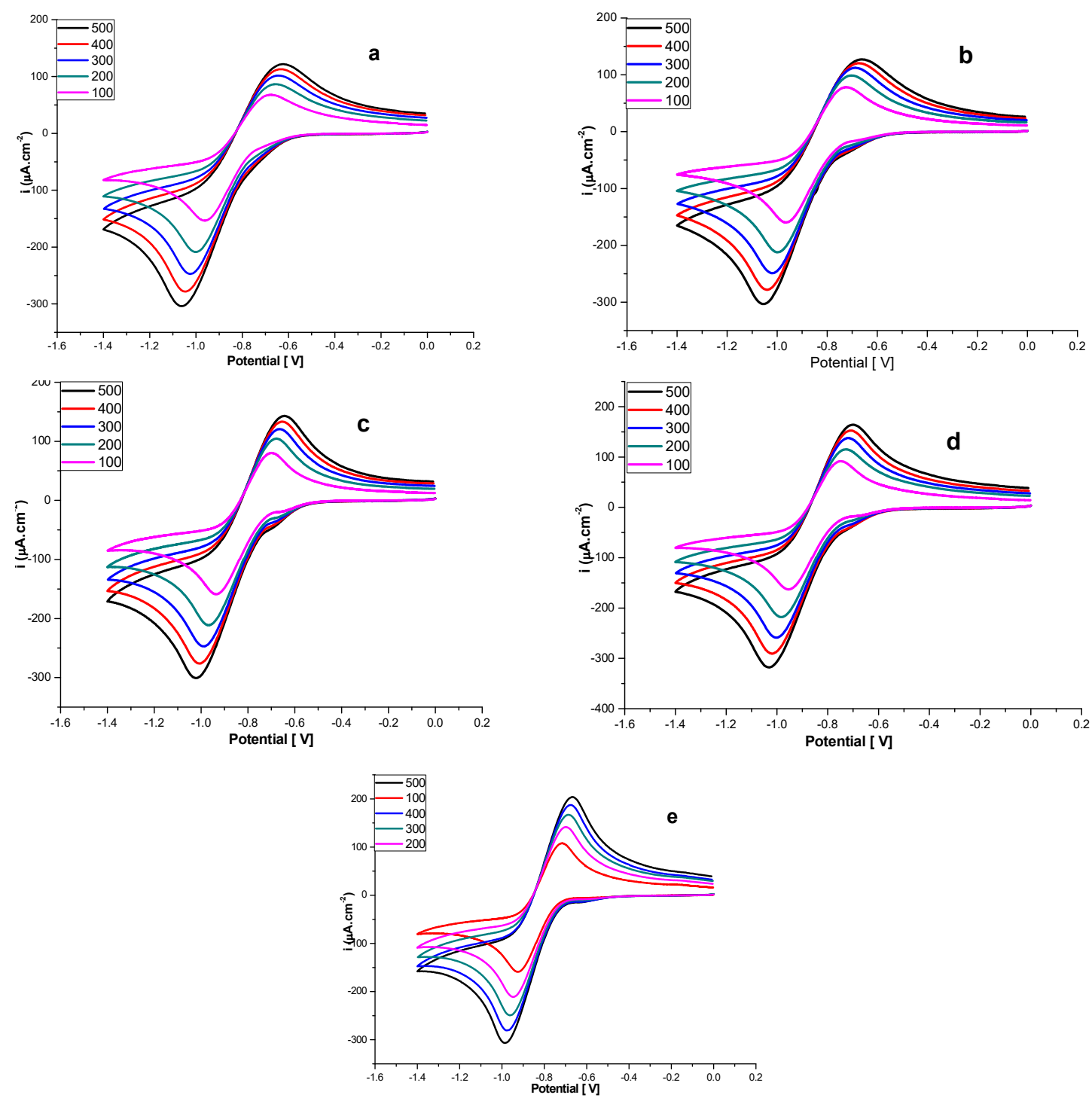

Fig.4. Succession of cyclic voltammograms at GC electrode in oxygen-saturated $\mathrm{DMF} / 0.1 \mathrm{TBFP}$ at different scan rates ranging from 100 to $500 \mathrm{mV} / \mathrm{s}$, (a) $\mathrm{O}_{2}^{-}{ }^{-}$-Kondor, (b) $\mathrm{O}_{2}^{-}$-Bartina, (c) $\mathrm{O}_{2}^{-}$-Spunta, (d) $\mathrm{O}_{2}^{-}-$Kuroda and (e) for $\mathrm{O}_{2}^{\cdot}$ 


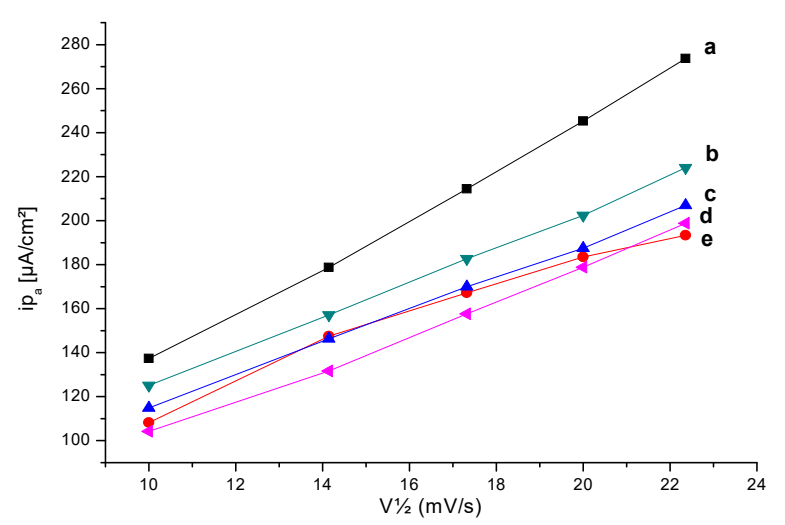

Fig.5. $\mathrm{ip}_{\mathrm{a}}$ versus $\mathrm{v}^{1 / 2}$ plots of oxygen-saturated DMF in the absence (a) and in presence of 0.4 $\mathrm{ml}$ of the extract of kuroda (b), spunta (c), bartina (d) and kondor (e)

Table 4. Diffusion coefficient values

\begin{tabular}{|l|l|l|l|}
\hline Sample & Equation & $\mathbf{R}^{2}$ values & $\mathbf{D}\left(\mathbf{c m}^{2} / \mathbf{s}\right)$ \\
\hline $\mathrm{O}_{2}^{-}$ & $\mathrm{y}=11.046 \mathrm{x}+24.721$ & 0.998 & $1.87 \mathrm{x} 10^{-6}$ \\
\hline $\mathrm{O}_{2}^{-}-$-Kondor & $\mathrm{y}=7.6929 \mathrm{x}+25.282$ & 0.997 & $9.09 \times 10^{-7}$ \\
\hline $\mathrm{O}_{2}^{-}$-Bartina & $\mathrm{y}=6.8567 \mathrm{x}+44.991$ & 0.978 & $7.22 \times 10^{-7}$ \\
\hline $\mathrm{O}_{2}^{-}-$-Spunta & $\mathrm{y}=7.3768 \mathrm{x}+41.425$ & 0.999 & $8.36 \times 10^{-7}$ \\
\hline $\mathrm{O}_{2}^{-}-$-Kuroda & $\mathrm{y}=7.941 \mathrm{x}+45.149$ & 0.999 & $9.68 \times 10^{-7}$ \\
\hline
\end{tabular}

\section{REFERENCES}

[1] Turpaev KT. Reactive oxygen species and regulation of gene expression. Biochemistry (Moscow) 2002;67:28192.

[2] Kunwar A, Priyadarsini KI. Free radicals, oxidative stress and importance of antioxidants in human health. J Med Allied Sci 2011;1:5360.

[3] Davies KJ. Oxidative stress: the paradox of aerobic life. Biochem Soc Symp 1995;61:131.

[4] Krishnaiah D, Sarbatly R, Bono A (2007) Phytochemical antioxidants for health and medicine: A move towards nature. Biotechnol Mol Biol Rev 1: 97-104.

[5] Rice-Evans, C.; Miller, N.J.; Paganga, G. Structure antioxidant activity relationships of flavonoids and phenolic acids. Free Radic. Biol. Med. 1996, 20, 933-956. [CrossRef]

[6] Robak, J.; Gryglewski, R.J. Flavonoids are scavengers of superoxide anions. Biochem. Pharmacol. 1988, 37, 837-841.

[7] Majer, P.; Neugart, S.; Krumbein, A.; Schreiner, M.; Hideg, É. Singlet oxygen scavenging by leaf flavonoids contributes to sunlight acclimation in Tilia platyphyllos. Environ. Exp. Bot. 2014, 100, 1-9. 
[8] Sánchez-Moreno, C.; Larrueri, J.A.; Saura-Calixto, F. A procedure to measure the antiradical efficiency of poliphenols. J. Sci. Food Agric. 1998, 76, 270 \pm 276

[9] Re, R.; Pellegrini, N.; Proteggente, A.; Pannala, A.; Yang, M.; Rice-Evans, C. Antioxidant activity applying an improved ABTS radical cation decolorization assay. Free Radic. Biol. Med. 1999, 26, 1231-1237.

[10] Singleton, V.L., Rossi, J.A.: Colorimetry of total phenolics with phosphomolybdic phosphotungstic acid reagents, American Journal of Enology and Viticulture, 1965, 16, 144158 ;

[11] Zou, Y., L , Y., Wei, D., 2004. Antioxidant activity of a flavonoid-rich extract of Hypericum perforatum L., in vitro. J. Agric. Food Chem. 52, 5032-5039.

[12] Ohinishi, M. Morishita, H. Iwahashi, H. Shizuo, T. Yoshiaki, S. Kimura, M.and Kido, R. (1994) Inhibitory effects of chlorogenic acids on linoleic acid peroxidation and haemolysis. Phytochemistry $36,579-583$.

[13] C. Le Bourvellec, D. Hauchard, A. Darchen, J.L. Burgot, M.L. Abasq, Talanta (2008). doi:10.1016/j.talanta.2008.01.007

[14] N. Blanc, D. Hauchard, L. Audibert, E. Ar Gall, Talanta (2011). doi:10.1016/j.talanta.2011.01.034

[15] Chew AL, Jessica JJA, Sasidharan S. 2012. Antioxidant and antibacterial activity of different parts of Leucas aspera. Asian Pac J trop Biomed 2:176-180

[16] X. Lu, K. Zhu, M. Zhang, H. Liu, J. Kang, J. Biochem. Biophys. Methods 52, 189 (2002)

[17] M. Ozsoz, A. Erdem, P. Kara, K. Kerman, D. Ozkan, Electroanalysis 15, 613 (2003)

[18] X. Chu, G.L. Shen, J.H. Jian, T.F. Kang, B. Xiong, R.Q. Yu, Anal. Chim. Acta 373, 29 (1998)

[19] M.T. Carter, M. Rodriguez, A. Bard, J. Am. Chem. Soc. 111, 8901 (1989).

[20] Feng Q, Li NQ and Jiang YY (1997). Electrochemical studies of porphyrin interacting with DNA and determination of DNA. Analytica Chimica Acta., 344: 97-104.

[21] S. Ahmed, F. Shakeel, Pak. J. Pharm. Sci. 25(3), 501 (2012)

[22] C.M.A. Brett, A.M.O. Brett, Electrochemistry: Principles, Methods and Applications (Oxford Science University Publications, Oxford, 1993), p. 427.

\section{How to cite this article:}

Ben Haoua K, Lanez T. Evaluation of the antioxidant activity of potatoes by radical scavenging activity using $\mathrm{O}_{2}^{-}$and DPPH. J. Fundam. Appl. Sci., 2018, 10(1), 168-180. 